\title{
Editorial
}

\section{Community Development through Family Well-Being}

\author{
Nicolette Vanessa Roman*
}

\begin{abstract}
Child and Family Studies, The Department of Social Work, University of the Western Cape, Robert Sobukwe Road, Bellville, 7535, South Africa
\end{abstract}

The year 2014 was considered as the twentieth anniversary year of the family and in a sense acknowledges the important role of the family in society. Families are central to communities and one could almost consider the family-community connection to be a loop. In other words, when families are functioning well communities fare very well, which then relates back to families. But how are we to understand this important role of the family?

Families are defined in different ways. According to Braithwaite and Baxter [1] "a family is a social group of two or more persons characterized by ongoing interdependence, with long term commitments that stem from blood, law and affection". Chambers [2] believes that families are not a fixed concept but can rather be described beyond blood lines into a socially constructed concept. In South Africa, in terms of family policy, the family is defined "as a public group of people that is directly related (by blood), related by adoption or fostering or through marriage" [3].

In describing a family, there are often two very broad terms used which are functional and dysfunctional families. These descriptions are often determined by the processes or functions/practices between and amongst family members. Family functioning includes the manner in which family members relate to and with one another including how they search for goals, activities the family engages in together and separately, and acceptance of family practices. Furthermore, when a family is functioning well, family members hardly develop psychological problems, they perform tasks together, are able to deal with problems, and have understandable restrictions [4]. These are well functioning families, but families also do not function very well and these families could be considered as unhealthy and dysfunctional, often described as at-risk [5]. Both terms have consequences especially for future adults.

The way in which families function affects individudal well-being [6]. Furthermore, this assists family members to manage difficulty, unfavourable life experiences and trauma [7]. Dysfunctional families are challenged in parenting their children and communicating effectively with other family

\footnotetext{
*Address correspondence to this author at the Child and Family Studies, The Department of Social Work, University of the Western Cape, Robert Sobukwe Road, Bellville, 7535, South Africa; Tel: 27(21) 9592011;

E-mail: nicoletteroman@gmail.com
}

members. Furthermore, substances are abused, physical, sexual and emotional abuse are present and children lack support and care. Within these families, there is the daily challenge of meeting the needs of family members. This could be due to the socio-economic circumstances of the family which in turn deprives family members of necessary resources and other social support. As a result, this undermines the ability of family members to perform expected functions and consequently results in the exposure to risk. Subsequently, at-risk families need additional support in order to cope with the myriad of challenges they face. This support may be in the form of other family members, community members or from government. Additionally, this support could also strengthen the family. Families should be seen as the entry point for service delivery and the subsequent building and development of communities [3]. Therefore, family relations, which are good and strong are important for the wellbeing of the individual, family and community [7]. In other words, family wellbeing is a concept that goes beyond economic wealth and includes physical and emotional health as well as safety and good quality relationships [7]. Similarly, family well-being and family functioning assume that families work best and contribute to society when there is a balance between the economic and non-economic factors [8] but it is very complex because family wellbeing is a multi-dimensional concept with different dimensions. These include providing financial support, good housing or access to services [9]. How does family well-being then relate to community development?

The creation, development and growth of communities is dependent on families. For example, when families are not doing well, the family members will act out that is outside of the family. This acting out often occurs within the community and could be the engaging in antisocial behavior, substance abuse, violence, etc. These behaviours subsequently break down communities instead of building them up. The same could be said for the effects of family wellbeing. Tsey et al. [10] found that family wellbeing is an enabler for people to take control and responsibility of their own situations but more importantly, once they are able to do this, there is a ripple effect on increasing harmony and capacity to address issues within the wider community.

Clearly, there is a relationship between family wellbeing and the overt and covert development of communities but 
the control and responsibility rests with the family. In this special issue, six articles highlight issues in the family which have consequences for family members and the community, either overtly or covertly. The article of Frantz, Sixaba \& Smith focuses on family structure and the effects on health risk behavior of young people in Africa. This article highlights the plight of orphans living with caregivers, the definitive relationship between sexual risk behavior and family structure and provides the evidence that sexual risk behaviors loops back to HIV/AIDS in African countries. In this article gender, race and culture play a role in the relationship. In the article by Ryan, Roman \& Okwany parental monitoring and communication are explored as important in the prevention, delay and reduction of substance abuse and risky sexual activity. These studies suggest that culture acts as a buffer against adolescent risk behaviors and that the mental health of parents is also important in the monitoring and communication with their adolescents. The Jacobs \& Jacobs study focuses on mothers who are alcoholics and provides family narrations of secrecy, shame and silence but also highlights coping and recovery for alcoholics. Londt, Davids \& Wilson used Social Learning Theory as a lens to understand the role of the family in the chronic denial of imprisoned sex offenders. These imprisoned sex offenders were raised in single-parent households with absent fathers, domestic violence substance abuse, unsatisfactory support and compromised parenting styles were prevalent. In the Mukasano, Schenck \& van der Merwe article, a qualitative study explores parents' experiences of their adolescents engaging in mobile texting. Parents find themselves having to monitor and negotiate rules and expectations with their adolescents. The study emphasizes the importance of communication and trust, respect and preparing for the disengagement process between parent and child. The final article of Jooste \& Maritz is an exploration of the perceptions of healthcare professionals and family members regarding youth's experiences of trauma. This article found that when youth experience trauma, there is a ripple effect onto other family members and the larger community which resulted in the entire system feeling helpless and depleted of resources to cope.

\section{REFERENCES}

[1] Braithwaite DO, Baxter LA. "You're my parent but you're not": Dialectical tensions in stepchildren's perceptions about communicating with the Nonresidential parent. J Appl Comm Res 2006; 34(1): 30-48.

[2] Chambers D. Sociology of family life. Change and diversity in intimate relations. UK: Polity Press 2012.

[3] Department of Social Development. White paper on families in South Africa. July 2013.

[4] Vliem SJ. Adolescent coping and family functioning in the family of a child with autism. Unpublished doctoral dissertation USA: The University of Michigan 2009.

[5] Bevcar D, Bevcar R. Family therapy. A systematic integration. $7^{\text {th }}$ ed. Boston: Allyn \& Bacon 2009.

[6] Botha F, Booysen F. Family functioning and life satisfaction and happiness in South African Households. S Afr Soc Indic Res 2014; 119(1): 163-82.

[7] Walker R, Shepherd C. Strengthening aboriginal family functioning: what works and why? Australia: AFR Clearing House 2008.

[8] McKeown K, Pratschke J, Haase T. Family well-being: what makes a difference? Dublin: Trutz Haase - Social \& Economic Consultant 2003.

[9] Fahey TI, Keilthy P, Polek E. Family relationships and family wellbeing: a study of the families of the nine year-olds in Ireland. Dublin: University College Dublin and the Family Support Agency 2012.

[10] Tsey K, Whiteside M, Deemal A, Gibson T. Social determinants of health, the 'control factor', and the family wellbeing empowerment programme. Australas Psychiatr 2003; 11(Suppl): S34-9.

(C) Nicolette Vanessa Roman; Licensee Bentham Open.

This is an open access article licensed under the terms of the Creative Commons Attribution Non-Commercial License (http://creativecommons.org/licenses/ by-nc/3.0/) which permits unrestricted, non-commercial use, distribution and reproduction in any medium, provided the work is properly cited. 